\title{
Gene expression profiling for monitoring graft rejection in heart transplant recipients
}

\author{
M.G. Crespo-Leiro ${ }^{\mathrm{a}}$, M.J. Paniagua-Martín ${ }^{\mathrm{a}}$, M. Hermida-Prieto ${ }^{\mathrm{b}}$, A. Castro- \\ Beiras $^{\mathrm{a}, \mathrm{b}}$ \\ ${ }^{a}$ Unidad de Insuficiencia Cardíaca y Trasplante Cardiaco, Hospital Universitario A Coruña, La Coruña, \\ Spain \\ ${ }^{b}$ Instituto de Ciencias de la Salud, Universidad de A Coruña, La Coruña, Spain
}

\begin{abstract}
Heart transplantation is a life-prolonging therapy for many patients with stage $\mathrm{D}$ heart failure and other forms of advanced heart disease. However, graft rejection and/or immunosuppression-related side effects are major causes of morbidity and death among heart transplant patients. Graft rejection monitoring remains a challenge. It would be desirable to be able to detect rejection early enough and specifically enough to prevent allograft dysfunction without unnecessary overimmunosuppression. Hitherto, the main technique employed in monitoring the rejection status of a transplanted heart has been endomyocardial biopsy (EMB), which allows rejection to be screened for and monitored on the basis of the extent and distribution of lymphocytic infiltrates and associated myocardial damage. However, EMB has significant limitations: it is invasive, its sensitivity is limited by sampling efficacy, and it suffers from considerable between-observer variability. Although many noninvasive techniques have been investigated, none so far has proved able to match the performance of EMB. Currently, a multiparametric approach is employed that comprises clinical examination for signs or symptoms of heart failure, EMBs, drug level monitoring, allograft function tests (mainly echocardiographic studies), and screening for allograft vasculopathy. Gene expression profiling may be a promising tool for this purpose.
\end{abstract}


HEART TRANSPLANTATION is a life-prolonging procedure for many patients with stage D heart failure and other forms of advanced heart disease. ${ }^{1}$ However, even with the latest advances in immunosuppression, graft rejection is a major cause of death among heart transplant patients. ${ }^{2}$ According to the Registry of the International Society for Heart and Lung Transplantation (ISHLT), rejection causes $12 \%$ of deaths occurring between 1 and 12 months after heart transplantation, ${ }^{3}$ and $20 \%$ to $50 \%$ of patients suffer at least 1 rejection episode during the first year posttransplantation. ${ }^{4}$ On the other hand, immunosuppression-related side effects lead to high morbidity and mortality rates. ${ }^{2,3}$ Graft rejection monitoring is still a challenge. It would be desirable to be able to detect rejection early enough and specifically enough to prevent allograft dysfunction without unnecessary overimmunosuppression. Gene expression profiling (GEP) seems to be a promising tool for this purpose. ${ }^{5}$

\section{SCREENING FOR AND MONITORING CARDIAC REJECTION: CLINICAL METHODS}

Hitherto, the main technique employed in monitoring the rejection status of a transplanted heart has been endomyocardial biopsy (EMB), which allows rejection to be screened for and monitored on the basis of the extent and distribution of lymphocytic infiltrates and associated myocardial damage. ${ }^{6}$ The goal of periodic EMB is to detect acute rejection before allograft dysfunction occurs. The latest version of the ISHLT EMB grading scheme ${ }^{7}$ establishes 4 categories: 0R (absence of rejection); 1R (mild rejection: presence of an interstitial and/or perivascular infiltrate, with or without a focus of myocyte damage); $2 \mathrm{R}$ (moderate rejection: presence of 2 or more infiltrate foci with associated myocyte damage); and 3R (severe rejection: presence of a diffuse infiltrate with multifocal myocyte damage and/or edema, vasculitis, or hemorrhage). The letter "R" denotes "Revised Classification" to avoid confusion with the previous scheme, the 1990 working formulation. ${ }^{8}$

EMB has significant limitations: it is invasive; it is expensive, ${ }^{9} ;$ its sensitivity is limited by sampling efficacy; it suffers from considerable between-observer variability; and it is difficult to interpret nodular endomyocardial infiltrates (so-called "Quilty lesions"). ${ }^{10}$ Also, although the incidence of complications is very low when EMB is performed by experienced staff, severe complications can arise, including pneumothorax, bleeding, pericardial tamponade secondary to perforation of the right ventricle, arrhythmias, fistulas between a coronary artery and the right ventricle, tricuspid regurgitation, damage to the carotid or femoral artery, and arterial-venous fistulas. ${ }^{11}$ There is no consensus among heart transplant centers or countries regarding the frequency with which EMBs should be performed, or for how long they should continue to be performed, but the current trend is to reduce their number; most US centers limit periodic EMBs to the first 5 years following heart transplantation, ${ }^{12}$ and most Spanish centers to the first year. ${ }^{13}$ The role of EMBs for rejection screening continues to be debated. ${ }^{14,15}$

Many noninvasive techniques have been investigated as regards their capacity for early detection of rejection, including echocardiography, radionuclide imaging, magnetic resonance imaging, intramyocardial electrograms, immune system monitoring, and biochemical parameters. ${ }^{16-18}$ However, none of them so far has proved able to match the performance of EMB. Currently, a multiparametric approach is employed that comprises clinical examination for signs or symptoms of heart failure, EMBs, drug level monitoring, allograft function tests (mainly echocardiographic studies), and screening for allograft vasculopathy. ${ }^{12}$ At the same time, it is mandatory to be on the lookout for side effects or complications of immunosuppressive therapy, particularly nephrotoxicity, infection, and cancer. 


\section{GENE EXPRESSION PROFILING AND HEART TRANSPLANTATION}

An approach that currently promises to be of utility is based on correlations between clinical states and the expression of certain genes. Although DNA defines a person's biological potential, it is the active transcription of DNA to RNA, followed by translation to protein that realizes this potential in accordance with his or her history, environmental context, and clinical situation. If a GEP can be identified that is sufficiently characteristic of a given physiological state, this profile can then be used to test whether the individual patient exhibits the state in question. If the GEP becomes manifest before clinical, biochemical, or histological signs, this allows earlier detection of disease states; and if it appears in tissue that can be obtained noninvasively, it may allow noninvasive diagnosis of conditions that were previously best diagnosed invasively. In certain cases, a GEP may indicate not a current or imminent disorder, but a physiological state that correlates with the future development of disease.

Genes that are up-regulated during acute cellular rejection after heart transplantation are involved in a wide range of functions, including $\mathrm{T}$-cell activation and migration, natural killer cell activation, stem cell mobilization, hematopoiesis, platelet function, alloimmune recognition, and steroid responsiveness. GEPs have been obtained both from heart tissue ${ }^{19}$ and from peripheral blood mononuclear cells (PBMC). ${ }^{20-22}$ For screening and monitoring purposes, the latter source has the great advantage over EMB of being noninvasive, which not only eliminates the risk of EMB-related complications, but also allows more frequent testing.

Schoels et al. ${ }^{20}$ took 58 blood samples from 44 patients at the time of EMB and used real-time quantitative polymerase chain reaction (PCR) to study the expression of 39 genes, including cytokines and chemokines, in PBMC. PBMC from patients with ISHLT EMB grades $\geq 2$ (ISHLT old classification ${ }^{8}$ ) differed significantly from those of patients with grades $<2$ as regards expression of the genes for perforin, CD95 ligand, granzyme B, RANTES, CXCR3, COX2, ENA 78 , and TGF- $\beta 1$, and a group of 5 was identified (perforin, CD95L, RANTES, COX2, and SEC7/TIC) that, with appropriate thresholds, discriminated between the 2 EMB grade groups with a sensitivity of $84 \%$ and a specificity of $82 \%$.

PCR methods can only handle up to about 50 genes at a time. Much more efficient for the purposes of identifying GEPs are DNA microarrays, which can carry representatives of all the genes in the genome. In a study in which they compared PBMC from 7 patients of EMB grade $\geq 3 \mathrm{~A}$ (according to ISHLT old classification ${ }^{8}$ ) and 7 of grade $\leq 1 \mathrm{~A}$ with regard to 22,215 DNA transcripts, Horwitz et $\mathrm{al}^{21}$ identified 91 transcripts (not all from different genes) that had significantly altered levels in the patients with rejection, and were able to discriminate between the groups with and without rejection by applying a clustering algorithm to data for 40 of these 91 . Furthermore, when patients with rejection had been treated and their rejection largely resolved, they exhibited profiles intermediate between their previous (rejection) profiles and those of patients without rejection, thus confirming the relevance of the corresponding genes to rejection. The involvement of the apoptosis-related gene CFLAR and the oxidative stress-related gene SOD2 was confirmed by real-time quantitative PCR.

In the Cardiac Allograft Gene Expression Observational (CARGO) study, ${ }^{23}$ to date the largest and most systematic investigation of GEP for diagnosis of heart graft rejection, an RNA microarray of 50-mer oligonucleotides representing 7370 genes identified 97 genes as candidate biomarkers when used to analyze gene expression in 285 PBMC samples from 98 patients (247 corresponding to ISHLT grade 0 EMB specimens and 38 to specimens with ISHLT grade $\geq 3 \mathrm{~A}$ ). Together with a further 155 genes known to be related to these 97 or otherwise involved in transplant rejection, their utility as markers of rejection was further examined by statistical workup of data from quantitative PCR analyses of 36 PBMC samples corresponding to grade $\geq 3 \mathrm{~A}$ rejection and 109 corresponding to grade 0 EMBs (most of these samples had not been screened for gene expression by microarray analysis). Eventually, a discriminant equation involving a group of 11 genes was developed that, on the basis of its application to a set of 281 samples from heart transplant patients $\geq 1$ year postoperation that was representative of the clinically observed EMB grade distribution, and using a diagnostic score threshold favoring negative predictive value (NPV), was estimated to have an NPV of $99.6 \%$, a positive predictive value (PPV) of $6.8 \%$, a 
sensitivity of $88.9 \%$, and a specificity of $69.4 \%$ for grade $\geq 3$ A rejection. Using this equation, PCR of PBMC can allow patients with subthreshold scores to be spared the risk involved in routine surveillance EMB. The CARGO II study is currently being carried out to validate these results in an independent, mainly European, population.

An unexpected and interesting feature of the CARGO data is that grade 1B EMB samples were associated with PBMC test scores similar to those of grade $\geq 3 \mathrm{~A}$ samples and significantly higher than those of grade 2 samples (as well as grades $1 \mathrm{~A}$ and 0 ). ${ }^{23,24}$ Although the import of this finding is still unclear, it suggests (if not the result of a combination of tissue sampling error and misclassification of EMB specimens by pathologists) that rejection, as reflected by PBMC GEPs, may be a 2-phase process. It was also noted that test scores in general tended to rise during the first year posttransplantation, and with them the optimal threshold for detection of rejection. ${ }^{23}$ Starling et $\mathrm{al}^{25}$ using the test version recently given FDA market clearance as the AlloMap Molecular Expression Test (XDx, Brisbane, Calif, United States), found that this rise appeared to be largely due to weaning from steroids after heart transplantation, and concluded that the AlloMap test might be useful for monitoring this process as well as for ruling out rejection. Allograft vasculopathy has also been reported to be associated with higher AlloMap scores. ${ }^{26}$

The CARGO/AlloMap studies mentioned above correlated test scores with current EMB status. The same research group also found that test scores could predict EMB-proven rejection weeks or months prior to the event, ${ }^{27}$ and that testing shortly after heart transplantation allowed the classification of patients as having low, medium, or high risk of future rejection. ${ }^{28}$ On the other hand, early posttransplantation ischemic injury has been reported to be associated with higher AlloMap scores recorded an average of 34 months after heart transplantation. ${ }^{29}$

Although the performance of the AlloMap test has been tested in a large number of patients using EMB results as a reference method, EMB has significant shortcomings, notably tissue sampling error and between-pathologist differences in interpretation. The Invasive Monitoring Attenuation Through Gene Expression (IMAGE) study is currently being carried out to compare the AlloMap with EMB in regard to relevant clinical outcomes (graft dysfunction, rejection with hemodynamic compromise, death, EMB-related complications), quality of life, and resource utilization. $^{30}$

In those of the above studies that concerned rejection, it was cellular rejection that was considered. An important recent development has been the analysis of CARGO study data to identify a GEP for antibody-mediated rejection. ${ }^{31}$ This work is still in progress, but the results obtained so far are promising and indicate cross-linking between the processes of cellular and antibody-mediated rejection.

In conclusion, the potential benefits of GEP of organ graft recipients are many. ${ }^{32}$ First, it eventually may be possible to diagnose rejection noninvasively and before tissue injury occurs; currently, it certainly seems possible to restrict the use of invasive techniques to a high-risk subgroup of patients identified by GEP at low cost. It has been estimated that the use of the AlloMap test could save US hospitals more than $\$ 15.7$ million annually. ${ }^{5,9}$ Second, GEP may also allow prognosis of the outcome of rejection, and of responsiveness to therapy; prediction of future allograft function; and the individualization or optimization of immunosuppressive therapy and changes thereof. Finally, it may help in the development of mechanism-based therapy. Further studies are needed to fully address these important issues.

\section{AUTHOR DISCLOSURE}

M.G. Crespo-Leiro and M. Hermida-Prieto acknowledge participation in the CARGO II study. 


\section{REFERENCES}

1. Hunt SA: Taking heart-cardiac transplantation past, present, and future. N Engl J Med 355:231, 2006

2. Almenar-Bonet L: [Spanish Heart Transplantation Registry. 18th Official Report of the Spanish Society of Cardiology Working Group on Heart Failure, Heart Transplantation and Associated Therapies (1984-2006)]. Rev Esp Cardiol 60:1177, 2007

3. Taylor DO, Edwards LB, Aurora P, et al: Registry of the International Society for Heart and Lung Transplantation: Twenty-fifth Official Adult Heart Transplant Report-2008. J Heart Lung Transplant 27:943, 2008

4. Starling RC, Pham M, Valantine H, et al: Molecular testing in the management of cardiac transplant recipients: initial clinical experience. J Heart Lung Transplant 25:1389, 2006

5. Mehra MR, Feller E, Rosenberg S: The promise of protein-based and gene-based clinical markers in heart transplantation: from bench to bedside. Nat Clin Pract Cardiovasc Med 3:136, 2006

6. Tan CD, Baldwin WM III, Rodriguez ER: Update on cardiac transplantation pathology. Arch Pathol Lab Med 131:1169, 2007

7. Stewart S, Winters GL, Fishbein MC, et al: Revision of the 1990 working formulation for the standardization of nomenclature in the diagnosis of heart rejection. J Heart Lung Transplant 24:1710, 2005

8. Billingham ME, Cary NR, Hammond ME, et al: A working formulation for the standardization of nomenclature in the diagnosis of heart and lung rejection: Heart Rejection Study Group. The International Society for Heart Transplantation. J Heart Transplant 9:587, 1990

9. Evans R, Williams $\mathrm{G}$, Baron $\mathrm{H}$, et al: The economic implications of noninvasive molecular testing for cardiac allograft rejection. Am J Transplant 5:1553, 2005

10. Marboe C, Billingham M, Eisen H, et al: Nodular endocardial infiltrates (Quilty lesions) cause significant variability in diagnosis of ISHLT grade 2 and $3 \mathrm{~A}$ rejection in cardiac allograft recipients. J Heart Lung Transplant 24:S219, 2005

11. Nguyen V, Cantarovich M, Cecere R, et al: Tricuspid regurgitation after cardiac transplantation: how many biopsies are too many? J Heart Lung Transplant 24:S227, 2005

12. Hunt SA, Haddad F: The changing face of heart transplantation. J Am Coll Cardiol 52:587, 2008

13. Crespo Leiro M, Almenar Bonet L, Alonso Pulpon L, et al: Conferencia de Consenso de los Grupos Españoles de Trasplante Cardiaco. Rev Esp Cardiol Supl 7:4B, 2007

14. Hamour IM, Burke MM, Bell AD, et al: Limited utility of endomyocardial biopsy in the first year after heart transplantation. Transplantation 85:969, 2008

15. Chen JM: "Take another little piece of my heart now": should endomyocardial biopsy remain the gold standard? Transplantation 85:934, 2008

16. Buchthal SD, Noureuil TO, den Hollander JA, et al: ${ }^{31} \mathrm{P}$-magnetic resonance spectroscopy studies of cardiac transplant patients at rest. J Cardiovasc Magn Reson 2:51, 2000

17. Cuppoletti A, Roig E, Perez-Villa F, et al: Value of NT-proBNP determinations in the follow-up of heart transplantation. Transplant Proc 37:4033, 2005

18. Arnau-Vives M, Almenar L, Hervas I, et al: Predictive value of brain natriuretic peptide in the diagnosis of heart transplant rejection. J Heart Lung Transplant 23:850, 2004

19. Morgun A, Shulzhenko N, Perez-Diez A, et al: Molecular profiling improves diagnoses of rejection and infection in transplanted organs. Circ Res 98:e74, 2006

20. Schoels M, Dengler TJ, Richter R, et al: Detection of cardiac allograft rejection by realtime PCR analysis of circulating mononuclear cells. Clin Transplant 18:513, 2004

21. Horwitz P, Tsai E, Putt M, et al: Detection of cardiac allograft rejection and response to immunosuppressive therapy with peripheral blood gene expression. Circulation 110:3815, 2004

22. Hermida-Prieto M, Crespo-Leiro MG, Paniagua MJ, et al: [Identification of a cardiac allograft rejection marker using microarray gene expression analysis in lymphocytes from heart transplant patients]. Rev Esp Cardiol 60:217, 2007

23. Deng MC, Eisen HJ, Mehra MR, et al: Noninvasive discrimination of rejection in cardiac allograft recipients using gene expression profiling. Am J Transplant 6:150, 2006

24. Bernstein D, Williams GE, Eisen H, et al: Gene expression profiling distinguishes a molecular signature for grade $1 \mathrm{~B}$ mild acute cellular rejection in cardiac allograft recipients. J Heart Lung Transplant 26:1270, 2007

25. Starling R, Deng M, Kobashigawa J: The influence of corticosteroids on the alloimmune molecular signature for cardiac allograft rejection. J Heart Lung Transplant 24:S65, 2005

26. Yamani MH, Taylor DO, Rodriguez ER, et al: Transplant vasculopathy is associated with increased AlloMap gene expression score. J Heart Lung Transplant 26:403, 2007 
27. Mehra MR, Kobashigawa JA, Deng MC, et al: Transcriptional signals of T-cell and corticosteroid-sensitive genes are associated with future acute cellular rejection in cardiac allografts. J Heart Lung Transplant 26:1255, 2007

28. Mehra MR, Kobashigawa JA, Deng MC, et al: Clinical implications and longitudinal alteration of peripheral blood transcriptional signals indicative of future cardiac allograft rejection. J Heart Lung Transplant 27:297, 2008

29. Yamani MH, Taylor DO, Haire C, et al: Post-transplant ischemic injury is associated with up-regulated AlloMap gene expression. Clin Transplant 21:523, 2007

30. Pham MX, Deng MC, Kfoury AG, et al: Molecular testing for long-term rejection surveillance in heart transplant recipients: design of the Invasive Monitoring Attenuation Through Gene Expression (IMAGE) trial. J Heart Lung Transplant 26:808, 2007

31. Cadeiras M, Bayern M, Burke E, et al: Gene expression profiles of patients with antibodymediated rejection after cardiac transplantation. J Heart Lung Transplant 27:932, 2008

32. Anglicheau D, Suthanthiran M: Noninvasive prediction of organ graft rejection and outcome using gene expression patterns. Transplantation 86:192, 2008 